\title{
Infection and Colonization by Staphylococcus aureus in a High Risk Nursery of a Brazilian Teaching Hospital
}

\author{
Helisângela de Almeida Silva ${ }^{1}$, Vânia O. Steffen Abdallah ${ }^{2}$, \\ Cláudia Lúcia Carneiro ${ }^{2}$ and Paulo P. Gontijo Filho ${ }^{1}$
}

\author{
Federal University of Uberlândia ${ }^{1}$, Clinical \\ Hospital of Federal University of Uberlândia ${ }^{2}$, \\ Uberlândia, MG, Brazil
}

\begin{abstract}
Neonates are susceptible to nosocomial infections due to immunological immaturity, prolonged hospital stay and the use of invasive procedures. We evaluated the incidence of infections and the prevalence of colonization by MRSA (Methicillin-resistant Staphylococcus aureus) and MSSA (Methilin-susceptible Staphylococcus aureus), as well as colonization risk factors. Staphylococcal infections were observed by analyzing medical records in the HICS (Hospital Infection Control Service) and the HRN (High Risk Nursery). Additionally, four inquiries concerning colonization prevalence were made for S. aureus, from January/2000 to December/2002. Clinical specimens from the nostrils, mouth and anus were cultivated in mannitol-salt agar plates and identification was made through standard methods. The frequency of neonates colonized by $S$. aureus was $49 \%$. MSSA was more prevalent $(57 \%)$ than MRSA $(43 \%)$. Risk factors related to the acquisition of MRSA were: low weight and antibiotic use., Hospital stay was the only variable significantly associated with colonization by $S$. aureus. The incidence of infections by $S$. aureus during the last three years was $2.18 \%$ (159 cases). Nine of them (5.5\%) were associated with MRSA and 150 (94.5\%) with MSSA. Staphylococcal infections were considered as invasive (sepsis) and noninvasive (conjunctivitis, cutaneous), corresponding to $31 \%$ and $69 \%$, respectively. The MRSA phenotype in infection was rare compared with methicillin-susceptible samples, although $\mathrm{S}$. aureus, MRSA and MSSA colonization rates were high.

Key Word: Staphylococcus aureus, neonates, infection, colonization and risk factors.
\end{abstract}

Nosocomial infections result in considerable morbidity and mortality among neonates, especially those in neonatal intensive care units [1-3].

The most frequently found microorganism involved in these infections is Gram-positive Staphylococcus aureus; it is considered the most important agent of endemic infections as well as outbreaks, followed by S. epidermidis, associated with central venous catheters $[4,5]$.

Although -methicillin-susceptible S. aureus (MSSA) continues to be the most frequent pathogen in Received on 10 March 2003; revised 05 August 2003.

Address for correspondence: Dr..Helisângela de Almeida Silva. Rua Lourdes de Carvalho, 330 Bairro: Santa Mônica. Phone: (55 34) 3210-0360. Fax: (55 34) 3218-2333. Zip code:38408-268 Uberlândia-MG., Brazil. E-mail: helisangelaa@yahoo.com.br

The Brazilian Journal of Infectious Diseases 2003;7(6):381-386 (C) 2003 by The Brazilian Journal of Infectious Diseases and Contexto Publishing. All rights reserved. hospitalized neonates, the resistant phenotype (MRSA) is of great importance, as it is associated with many outbreaks [6,7].

The umbilical cord, the perineum and the groin are the first sites to be colonized by $S$. aureus in neonates, the colonization of these mucocutaneous sites being an important risk factor for $S$. aureus infections [8]. Though the neonate can be colonized through contact with the mother, many populationbased studies provide good evidence that the nursery staff usually spreads this microorganism, and that the hands are the most important route of transmission $[8,9]$. Previous colonization is the most important risk factor for staphylococcal infections [10], being followed by premature birth, low weight, immunodeficiency, prolonged hospital stay, antimicrobial use, invasive methods and surgical interventions $[7,11,12]$. 
We evaluated the rates of infection, incidence, and colonization prevalence by MRSA and MSSA, as well as colonization risk factors in colonized neonates, from January, 2000, to December, 2002.

\section{Materials and Methods}

Hospital. This study was made at the High Risk Nursery (HRN) of the Clinics Hospital, Federal University of Uberlândia (HC-UFU), with approximately 45 beds, which attends at a tertiary level. This study was approved by the Commission of Ethics of this University.

Study design. Staphylococcus aureus infection data was obtained by analyzing neonate medical records of the Hospital Infection Control Service (HICS) and the HRN.

Four prevalence inquiries $(25 / 10 / 2000,11 / 09 / 2001$, 05/02/2002 and 23/08/2002) were made of $S$. aureus colonization. Clinical specimens were collected from all the neonates in the unit and an individual record was filled out with the demographic data, clinical, and intrinsic and extrinsic risk factors.

Microbiological techniques. Clinical specimens were collected by swabs, from the anus, mouth and nostril. The samples were taken to the laboratory in tubes containing "Trypticase Soy Broth" (TSB). They were cultivated in mannitol-salt agar plates and incubated at $37^{0} \mathrm{C}$ during 24 to 48 hours. The colonies were characterized as Staphylococcus through Gram staining and by the catalase test. Staphylococcus aureus identification was made by mannitol-salt agar fermentation. The cultures were kept in stock agar tubes containing $20 \%$ glycerol in a freezer $\left(-20^{\circ} \mathrm{C}\right)$. A sample of S. aureus ATCC 25923 were used as a control. MRSA samples were characterized through cultivation in screening agar containing $4 \% \mathrm{NACl}$ and $6 \mathrm{mg}$ oxacillin/mL [13].

Statistical analysis. The epidemiological data were analyzed by $X^{2}, t$ Student and exact Fisher tests by using the Epi-Info 5.0 program [14], considering $\mathrm{P}<$ 0.05 as significant.

\section{Results}

During the inquiries, 143 neonates were analyzed. The frequency of colonization by $S$. aureus was $49 \%$ (70/143). MSSA was more prevalent than MRSA, with colonization rates of $57 \%$ and $43 \%$, respectively. MRSA was more frequent only in the second inquiry (79\%) (Table 1).

Risk factors associated with colonization by MRSA and MSSA, as well as among children colonized by both when compared with children without $S$. aureus (control group) colonization are in tables 2 and 3.

Hospital stay was the only variable significantly associated with colonization by $S$. aureus $(\mathrm{P}<0.05$, Table 2). It was found that weight inferior to 1500 grams and antibiotic use were more frequent $(\mathrm{P}<0.05)$ in the group with MRSA than in the neonates colonized by MSSA (Table 3 ).

The incidence of S. aureus infections was $2.2 \%$, corresponding to 159 cases, with nine cases $(5.5 \%)$ associated with the MRSA phenotype and 150 (94.5\%) with MSSA (Table 4).

The clinical forms of staphylococcal infections were divided into invasive infections (31\%), including cases of sepsis, and non-invasive $(69 \%)$, including conjunctivitis and cutaneous infection, which were the most prevalent forms (Table 4).

\section{Discussion}

The epidemiology of nosocomial infections by MSSA and MRSA presents several different aspects. Infection by MRSA is more commonly associated with adult patients, particularly in those with the following risk factors: prolonged hospital stay, antimicrobial use, invasive procedures, surgeries and patients submitted to the hemodialysis or dialysis peritoneal [15]. MSSA infections are more prevalent in neonates, especially those with the following risk factors: premature birth, low weight, breathing syndromes, immunodeficiency, antimicrobial use, prolonged hospital stay, invasive methods and surgical interventions [12].

Risk factors associated with infections are the same as those related with colonization. The latter is 
Tab1e 1. Colonization by methicillin-resistant Staphylococcus aureus (MRSA) and methicillin-sensitive Staphylococcus aureus (MSSA) in neonates, based on four prevalence inquiries made from January 2000 to December 2002

\begin{tabular}{|c|c|c|c|c|c|c|c|}
\hline \multirow{3}{*}{ Date } & \multirow{3}{*}{$\begin{array}{c}\text { Neonates } \\
\mathbf{N}\end{array}$} & \multirow{2}{*}{\multicolumn{2}{|c|}{ Colonized neonates }} & \multicolumn{4}{|c|}{ Prevalence/Colonization } \\
\hline & & & & \multicolumn{2}{|c|}{ MRSA } & \multicolumn{2}{|c|}{ MSSA } \\
\hline & & $\mathbf{N}$ & $\%$ & $\mathbf{N}$ & $\%$ & $\mathbf{N}$ & $\%$ \\
\hline 10.25 .2000 & 35 & 13 & 37 & 3 & 23 & 10 & 77 \\
\hline 09.11.2001 & 35 & 19 & 54 & 15 & 79 & 4 & 21 \\
\hline 02.05 .2002 & 36 & 20 & 56 & 4 & 20 & 16 & 80 \\
\hline 08.23 .2002 & 37 & 18 & 49 & 8 & 44 & 10 & 56 \\
\hline Total & 143 & 70 & 49 & 30 & 43 & 40 & 57 \\
\hline
\end{tabular}

Table 2. Risk factors for acquiring Staphylococcus aureus colonization in neonates hospitalized from January 2000 to December 2002

\begin{tabular}{|c|c|c|c|c|c|c|}
\hline \multirow[b]{2}{*}{ Risk factor } & \multicolumn{2}{|c|}{$\begin{array}{c}\text { Colonized } \\
(\mathbf{n}=70)\end{array}$} & \multicolumn{2}{|c|}{$\begin{array}{l}\text { Not colonized } \\
\quad(n=73)\end{array}$} & \multirow[b]{2}{*}{$\mathbf{P}$} & \multirow[b]{2}{*}{ OR (CI) } \\
\hline & $\mathbf{N}$ & $\%$ & $\mathbf{N}$ & $\%$ & & \\
\hline \multicolumn{7}{|l|}{ Sex } \\
\hline Male & 44 & 63 & 36 & 49 & 0.143 & $1.74(1.85-3.59)$ \\
\hline \multicolumn{7}{|l|}{ Weight } \\
\hline$\leq 1500 \mathrm{~g}$ & 25 & 36 & 21 & 29 & 0.477 & $1.38(0.64-2.96)$ \\
\hline \multicolumn{7}{|l|}{ Apgar } \\
\hline $0-4$ & 5 & 7 & 4 & 5 & 0.948 & $1.33(0.29-6.21)$ \\
\hline $5-7$ & 51 & 73 & 44 & 60 & 0.156 & $1.77(0.83-3.81)$ \\
\hline $8-10$ & 14 & 20 & 25 & 34 & 0.084 & $0.48(0.21-1.09)$ \\
\hline \multicolumn{7}{|c|}{ Weeks of gestation } \\
\hline$\leq 36$ weeks & 39 & 56 & 37 & 51 & 0.663 & $1.22(0.60-2.49)$ \\
\hline Antibiotic use & 22 & 33 & 25 & 34 & 0.856 & $0.88(0.41-1.88)$ \\
\hline \multicolumn{7}{|c|}{ Length of Hospitalization ${ }^{1}$} \\
\hline$\geq 7$ days & 57 & 81 & 47 & 64 & $0.035^{*}$ & $0.41(0.18-0.95)$ \\
\hline Incubator care & 30 & 43 & 32 & 43 & 0.959 & $0.96(0.47-1.96)$ \\
\hline $\begin{array}{l}\text { Mechanical } \\
\text { ventilation }\end{array}$ & 11 & 16 & 10 & 14 & 0.917 & $1.17(0.42-3.26)$ \\
\hline Invasive devices & 35 & 50 & 38 & 52 & 0.937 & $0.92(0.45-1.87)$ \\
\hline
\end{tabular}

OR: Odds rates, CI: Confidence intervals, ${ }^{1}$ Time between hospitalization and taking the samples.

${ }^{*} \mathrm{P} \leq 0.05$ - significant. 
Table 3. Risk factors for acquiring MRSA and MSSA colonization in neonates interned from January 2000 to December 2002

\begin{tabular}{|c|c|c|c|c|c|c|}
\hline \multirow[b]{2}{*}{ Risk factor } & \multicolumn{2}{|c|}{$\begin{array}{c}\text { MRSA } \\
(n=30)\end{array}$} & \multicolumn{2}{|c|}{$\begin{array}{c}\text { MSSA } \\
(n=40)\end{array}$} & \multirow[b]{2}{*}{$\mathbf{P}$} & \multirow[b]{2}{*}{ OR (CI) } \\
\hline & $\mathbf{N}$ & $\%$ & $\mathbf{N}$ & $\%$ & & \\
\hline \multicolumn{7}{|l|}{ Sex } \\
\hline Male & 16 & 53 & 28 & 70 & 0.238 & $0.49(0.16-1.47)$ \\
\hline \multicolumn{7}{|l|}{ Weight } \\
\hline$<1500 \mathrm{~g}$ & 16 & 53 & 10 & 25 & $0.029^{*}$ & $3.43(1.11-10.78)$ \\
\hline \multicolumn{7}{|l|}{ Apgar } \\
\hline $0-4$ & 4 & 13 & 1 & 2.5 & 0.203 & $6.00(0.57-149.37)$ \\
\hline $5-7$ & 21 & 70 & 30 & 75 & 0.846 & $0.78(0.24-2.55)$ \\
\hline $8-10$ & 5 & 17 & 9 & 22 & 0.762 & $0.69(0.17-2.66)$ \\
\hline \multicolumn{7}{|l|}{ Weeks of gestation } \\
\hline$<36$ weeks & 19 & 63 & 20 & 50 & $0.385 *$ & $1.73(0.59-5.10)$ \\
\hline Antibiotic use & 14 & 46 & 8 & 20 & $0.034^{*}$ & $3.50(1.08-11.58)$ \\
\hline \multicolumn{7}{|l|}{ Length of Hospitalization $^{1}$} \\
\hline$\geq 7$ days & 27 & 90 & 30 & 75 & 0.198 & $0.33(0.06-1.52)$ \\
\hline Incubator care & 15 & 50 & 15 & 37 & 0.422 & $1.67(0.57-4.88)$ \\
\hline $\begin{array}{l}\text { Mechanical } \\
\text { ventilation }\end{array}$ & 4 & 13 & 7 & 17 & 0.886 & $0.73(0.16-3.20)$ \\
\hline Invasive devices & 19 & 63 & 16 & 40 & 0.090 & $2.59(0.88-7.76)$ \\
\hline
\end{tabular}

OR: Odds rates, CI: Confidence intervals, ${ }^{1}$ Time between hospitalization and taking samples.

${ }^{*} \mathrm{P} \leq 0.05$ - significant.

Table 4. Incidence of infections by MRSA and MSSA and forms of infection observed in neonates interned at the HRN/UFU-HC from the first semester of 2000 to the second semester of 2002

\begin{tabular}{|c|c|c|c|c|c|c|c|c|c|c|}
\hline \multirow{3}{*}{$\begin{array}{l}\text { Semester/ } \\
\text { year }\end{array}$} & \multirow{2}{*}{\multicolumn{2}{|c|}{$\begin{array}{l}\text { Staphylococcal } \\
\text { infections }\end{array}$}} & \multicolumn{8}{|c|}{ Infection } \\
\hline & & & \multicolumn{2}{|c|}{ MRSA } & \multicolumn{2}{|c|}{ MSSA } & \multicolumn{2}{|c|}{ Invasive } & \multicolumn{2}{|c|}{ Non invasive } \\
\hline & $\mathbf{N}$ & $\%$ & $\mathbf{N}$ & $\%$ & $\mathbf{N}$ & $\%$ & $\mathbf{N}$ & $\%$ & $\mathbf{N}$ & $\%$ \\
\hline $1 / 2000$ & 14 & 1.22 & 2 & 0.17 & 12 & 1.05 & 6 & 43 & 8 & 57 \\
\hline $2 / 2000$ & 27 & 2.11 & 6 & 0.47 & 21 & 1.64 & 9 & 33 & 18 & 67 \\
\hline $1 / 2001$ & 35 & 2.43 & - & - & 35 & 2.43 & 4 & 11 & 31 & 89 \\
\hline $2 / 2001$ & 33 & 2.65 & 1 & 0.08 & 32 & 2.57 & 8 & 24 & 25 & 76 \\
\hline $1 / 2002$ & 32 & 2.72 & - & - & 32 & 2.72 & 15 & 47 & 17 & 53 \\
\hline $2 / 2002$ & 18 & 1.78 & - & - & 18 & 1.78 & 8 & 44 & 10 & 56 \\
\hline Total & 159 & 2.18 & 9 & 5.5 & 150 & 94.5 & 50 & 31 & 109 & 69 \\
\hline
\end{tabular}


considered the most important risk factor for illness [10].

Studies carried out in the USA concerning infection by $S$. aureus show that it causes clinically-significant infections in $10 \%$ to $60 \%$ of the hospital patients who acquire carriage [16]. On the other hand, studies performed in the United Kingdom demonstrated infection rates far less than $60 \%$, and probably less than the lower level of $10 \%[17,18]$.

Our results are similar to those found in the UK, less than 5\% infection in colonized patients. In the case of MRSA, only nine $(6 \%)$ infected patients were detected, even though $43 \%$ of the neonates were found to be colonized. Adock [19] described similar results in the USA. However, Loureiro et al. [11] found 50\% of the neonates to be colonized by MRSA, in a study made in a public hospital in Rio de Janeiro.

Brazilian HRNs and NICUs are always crowded, which contributes to cross infections [20]. Neonate hospital stay is usually prolonged, facilitating $S$. aureus colonization. This was an important observation in our study because hospital stay was the only variable significantly related to colonization by $S$. aureus $[11,21]$.

Resistant bacteria are more common in ICUs [22] than in other hospital units, due to greater risk factors and more antibiotic use $[23,24]$. We also found antibiotic use to be an important risk factor for colonization by MRSA.

Staphylococcus aureus is the second most common microorganism isolated from infections in NICUs [25]; methicillin-susceptible samples being the most common [26]. Such infections predominantly involve sepsis, pneumonia, cutaneous infection and conjunctivitis [4].

A recent study made in Rio de Janeiro by Loureiro et al [27] found 5.6\% infection, which was similar to our results. On the other hand, Tapia-Rombo et al. [2] observed 23.8\% infection in Mexico.

Most of infections we observed (69\%) were classified as non invasive (cutaneous, conjunctivitis); among the sepsis cases (31\%) the MRSA phenotype contributed only $10 \%$. Loureirol et al. [27] found that $93.3 \%$ of the cases of sepsis by $S$. aureus were caused by MRSA.
There is considerable use of antibiotics in HRNs, being stimulated by difficulties in the clinical diagnosis of sepsis and the high mortality in these units $[22,28]$. Approximately $75 \%$ of the neonates in NICU receive antibiotics until the third day of life, being more frequent in those of low weight [29].

Nagata et al. [21] in Londrina/PR, found that $46 \%$ of the neonates used antibiotics, which was more than in our study (34\%). Of the neonates colonized by MRSA, $47 \%$ were using antibiotics, while just $20 \%$ of the MSSA infected neonates used them.

In the control of infection/colonization in neonatal units a restriction in the use of antibiotics should be considered, with the implantation of educational measures [29].

The most effective methods for the reduction of infections are not always the most expensive ones, such as washing hands, considered the most important procedure in the prevention of nosocomial infections [21]

Our results show that while the policy to restrict the use of antibiotics , educational measures, prevention practices and rigid hand-washing policies adopted in the NICU has resulted in a low frequency of neonates infected by MRSA, on the other hand the situation is complex since about half of the children were found to be colonized by $S$. aureus.

\section{Acknowledgements}

Financial support was provided by CNPq.

\section{References}

1. Kawagoe J.Y., Segre C.A.M., Pereira C.R., et al. Risk factors for nosocomial infections in critically ill newborns: A 5year prospective cohort study. AJIC 2001;29:109-15.

2. Tapia-Rombo C.A., Ugarte-Torres R.G., et al. Risk factors for intrahospital infections in Newborns. Arch Med Research 2001;32:304-11.

3. Waggoner-Fontain L.A., Donowitz L.G. Infection in the Newborn. In: Wenzel R.P. eds. Prevention and Control Nosocomial Infections. Baltimore: Williams \& Wilkins, 1997.

4. Gaynes R.P., Edwards J.R. Jarvis W.R., et al. Nosocomial infections among neonates in high-risk nurseries in the United States. Pediatrics 1996; 98:357-61. 
5. Drews M.B. Ludwing A.C., Leititis J.U., Daschener F.D. Low birth weight and nosocomial infection in a neonatal intensive care unit. J Hosp Infect 1995;30:65.

6. Davies E.A., Emmerson A.M., Hogg G.M., et al. An outbreak of infection with a methicillin-resistant Staphylococcus aureus in a special care baby unit: Value of topical mupirocin and of traditional methods of infection control. J Hosp Infect 1987;10:187-97.

7. Corbell X., Dominguez M.A., Pujol M., et al. Staphylococcus aureus nasal carriage as a marker for subsequent staphylococcal infections in intensive care unit patients. Europ J Clin Microbiol Infect Dis 1997; 16:351-7.

8. Couto R.C., Pedrosa T.M.G., Tupinambás U. Rezende N.A. The effect of post-discharge surveillance and control strategies on the course of a Staphylococcus aureus outbreak in a newborn nursery. Braz J Infect Dis 2000;4:296-300.

9. Safdar N., Maki D.G. The commonality of risk factors for nosocomial colonization and infection with antimicrobialresistant Staphylococcus aureus, Enterococcus, Gramnegative Bacilli, Clostridium difficile and Candida. Ann Intern Med 2002;136:834-44.

10. Kluytmans J., Vanbelkum A., Verbrugh H. Nasal carriage of Staphylococcus aureus: Epidemiology, Underlying mechanisms, and associated risks. Clin Microbiol Rev 1997; 10:505-20.

11. Loureiro M.M., Moraes B.A., Quadra M.R.R., et al. Molecular Epidemiology of methicillin resistant Staphylococcus aureus isolated from newborns in a Hospital in Rio de Janeiro, Brazil. Mem Inst Oswaldo Cruz 2000;95:777-82.

12. Escobar G.J., Li D.K., Armstrong M.A., et al. Neonatal sepsis work ups in Infants $\geq 2000$ grams at birth: a population-based study. Pediatrics 2000;106:256-65.

13. National Committee for Clinical Laboratory Standards. Methods for dilution Antimicrobial Susceptibility Tests for Bacteria That Grow Aerobically. Seventh ed; Approved Standard. Wayne, P.A.: NCCLS, 2000.

14. Dean A.G., Dean J.A., Burton A.H., Dicker R.C. Epi-Info, versão 5.0: a word processing, database and statistics program for Epidemiology on microcomputers. Stone Mountain G.A.: USD, Inc: 2000.

15. Talon D., Woronoff-Lemsi M.C., Limat S. Bertrond X., et al. The impact of resistance to methicillin in Staphylococcus aureus bacteremia on mortality. Europ J. Intern Med 2002;13:31-6.

16. Farrington M., Redpath C., Trindle C., Brown N. Controlling MRSA. J Hospit Infect 1999;41:251-2.

17. Barret S.P., Mummery R.V., Chattopadhyay B. Controlling MRSA. J Hospit Infect 1999;41:252-4.

18. Barret S.P., Mummery R.V., Chattopadhyay B. Trying to control MRSA causes more problems than it solves. J Hospit Infect 1998;39:885-93.
19. Adock P.M., Pastor P., Medly F., et al. Methicillin - resistant Staphylococcus aureus in two child care centers. J Infect Dis 1998; $178: 577-80$.

20. Maria N. Um alerta às autoridades. Jornal do Conselho Regional de Medicina do Estado do Rio de Janeiro 1999; November: 6.

21. Nagata E., Brito A.S.J., Matsuo T. Nosocomial infections in a neonatal intensive care unit: incidence and risk factors. AJIC 2002;30:26-31.

22. Hanberger A., Diekema D., Fluit A., et al Surveillance of antibiotic resistance in European ICUs. J Hospit Infect 2001;48:161-76.

23. Macgowan J.E., Tenover F.C. Control of antimicrobial resistance in the health care system. Infect Dis Clin North Am 1997; 11:297-311.

24. Monnet D.L. Methicillin-resistant Staphylococcus aureus and Its relationships to antimicrobial use: possible implication for control. Infect Control Hosp Epidemiol 1998; 19:5552-8.

25. Stool B.J., Gordon T., Korones S.B., et al. Late-onset sepsis in very low birth weight neonates: a report from the National Institute of Child Health and Human Development Neonatal Research Network. J Pediatr 1996; 129:63-71.

26. Siegel J.D. The newborn nursery. In: Bennett J.V., Brachman P.S. eds. Hospital Infections. Philadelphia: Lippincott-Raven, 1998.

27. Loureiro M.M., Moraes B.A., Quadra M.R.R., et al. Study of multi-drug resistant microorganisms isolated from blood cultures of hospitalized newborns in Rio de Janeiro City, Brazil. Braz J Microbiol 2002;33:73-8.

28. Mullet M.D., Cook E.F., Gallagher R. Nosocomial sepsis in the neonatal intensive care unit. J Perinatol 1998; $18: 112-5$.

29. Fonseca S.N.S., Ehrenkranz R.A., Baltimore R.S. Epidemiology of antibiotic use in a neonatal intensive care unit. Infect Control Hosp Epidemiol 1994; 15:156-62. 